\title{
Analysis of Competitiveness with Online Marketing Tools in Hungary
}

\author{
Katalin Tari \\ Faculty of Economics and Social Sciences, Szentlstván University Hungary \\ Nikolett Mihály \\ Faculty of Economics and Social Sciences, SzentIstván University Hungary
}

\begin{abstract}
In the world of marketing, innovative solutions and new development opportunities will always come into play. They play of the major factor in improving the competitiveness and for consumers needs as well. The aim of the study is to examine and compare the efficiency and effectiveness measurement of the online campaigns. At first, this study is arising the theoretical approaches and then points to the practical application differences and also wants to rank the effectiveness of online. The currently used Hungarian online measures (rate/index) are explained in this study by using the available practical literature. The in-depth interviews will be conducted with the consent of online shop managers and leader professionals of creative and advertisement agencies. Procession of the practical literature will include the online advertising methods ranked by the CPM (Cost per 1000 Impression) will imply the effectiveness of ads. Our research methodology followed qualitative strategy, on the base of content analyses of in-depth interviews of online experts $(\mathrm{N}=7)$. We recorded the conversation and then we transcribed the data. Our questions were structured. The questioning went between 10 March 2016 and 18 May. 7 persons have taken part in the research, regarding to their profession they were mid, - or top managers and had at least 4 maximum 15 years of experience. Regarding to their activities, there are who is planning, leading and following up marketing and/or creative campaigns - together with analyses - or with full-service of web shop, online legal advising, retargeting and optimization services. Each interviewee serves the business-to-business trade. Furthermore our aim is to present the Hungarian online advertising trends in 2016. This indication will show the effectiveness of different marketing tools, also the reach of online experts, which is a tool in increasing competitiveness. This research will point out the possible measuring methods and indications, which allows the integrated testing of performance on different channels.
\end{abstract}

Keywords: efficiency, efficiency measurement, online marketing, competitiveness JEL classification: A32

\section{Introduction}

Development of innovative solutions and efficacy, developmental opportunities of marketing and its tool-system have important role in marketing - in our case the online marketing - from point of view of all sectors of economics. The appropriate positioning, segmenting of target market, the usage of the properly structured sales promotion, as well as differentiated price, - and product-policy are well known tools of increment of efficiency. These play an important role in improvement of competitiveness as well as in satisfaction of customers' demands. 


\section{What kind of transition are we witnessing?}

The actuality of the topic is at high emphasis while the most developing industrial branch is the e-merchandizing, today. Reviewing the events of last decades, right after the transition, after the radical changes affecting economy and together with it the sector of marketing, now we live an essentially new boom of digital age which is called also as the 'golden era of e-trade.' (Virányi, 2014)

This intensive increment - on the base of estimations - will entirely define the formation of economy until 2018. On the base of the research of emarketer.com, the number of regular internet-users is going to reach the half of the population of Earth in 2 years, so this will slow the further increment down. 'The other reason for delay is the fact of the finite element number, which is the population of Earth. Related to Hungary, this slowing effect could be experienced last year, already. In 2010, the $55 \%$ of population of the country was regular internet users, while $72 \%$ of them have been using the internet regularly by 2014 and $74 \%$ of them were in 2015 . (KSH, 2016, Majláth et al., 2015) About reasons of this slowing increment we are going to write in section 'Introduction' more detailed, later. The firms build an increasing confidence in internet-users with proper utilization of online communication tools; the number of interactions is growing between the participants which may support reports of experience gained by word of mouth. The online firm appearing on online market can target a growing online customer layer with flexible opening hours and comparable prices; with various product ranges; by easy operation as well as everyday usage of smart phones.

\section{How to work on on-line market more effectively?}

The first step is to make the company's aims clear. The revenue growth and reputation as well as popularizing are in focus of marketing campaigns. Support of these aims enhances a more effective planning and targeting of campaigns by the most determining elements of the recent online age. In addition to it, the selection of the marketing channel is an unmissable factor, after the aims, which is impacted by target group, characteristics of the product/service, the competitors, the budget, the features and measurement of online media as well as other unique factors as time, urgency, the synergy-effects or the creative ideas.

The effectiveness of the campaign - which means the number of realized purchases - can be raised by tools used for many years among marketing agencies. This means the possibilities of the personalized optimizing tools as for example SEO, PPC also known as CPC, the follow-up of bounce rate, conversion optimization (CRO), click through rate (CTR), a call to action (CTA) and then the analyses, interpretation of incoming data as well as conclusions, which last 3 factors will be discussed later, in our study. (Szabó, 2008)

Everyone can launch the idea of running an online shop along with the broad proliferation of online trends. It is much easier to prepare and support the company's such decisions, today, reducing risks, or it can open up towards unprecedented cross-border markets. To do this, the web, and the presenting companies over there and customer follow-up of their products and/or services and, analyzing their antecedents and their actions provides the highest offer for personalized assistance to achieve $100 \%$ conversion rate - which is actually still inaccessible. (Fehér, 2013)

Our research goal is to demonstrate most frequently used tools, evaluation means of online and the practice-relevant offline marketing campaigns on business-to-

\footnotetext{
'Advertising and Marketing, "Internet to Hit 3 Billion Users in 2015", available at: http://www.emarketer.com/Article/Internet-Hit-3-Billion-Users-2015/1011602 (19/04/2016)
} 
business market in Hungary. Further aims are to evaluate of effectiveness and influence of them. Our results based on content analyses of structured in-depth interviews, recorded in professional context.

\section{Short review on the Hungarian e-trends}

As mentioned in the introduction, we wish to present the reasons for the slowing growth of Internet users, during the presentation topic. The migration and poverty there could stand in the background of the slowing pace of growth, in our opinion. In addition, the two groups of Internet surfers should be separated, in the beginning. Namely, those who do not buy, and those who buy online, since they are direct participants in the economy. While the figures show slowing growth of number of users, then the number of online shoppers will gradually grow. The intensive growth rate here has lagged in our country, so it is now gradually distributed throughout a prolonged period. The companies using online communication tools correctly are building an increasing confidence among users, the number of interactions that supports experiential reports obtained by the oral tradition - in a family/friend expression is increasing between the participants. By flexible opening hours and comparable prices; with a diverse range of products and easy operation and by extensive display support or by everyday use of smart phones the company is more widely and more efficiently able to target the customer base, if it advertises on online market. This growth is associated with the relatively positive evolution of the total costs and revenue. The conversion rate shows the fixed cost recovery. Therefore, it is important to clarify the concept for this reason, and also because of correct interpretation of our hypothesis. The conversion rate is not meaningful as itself, because it is necessary to define conversion goal/objectives and research question/s, first.

We use the conversion rate most commonly; in general form in case it shows the number of realized purchases, usually examining the online market aspects. The 3-5\% of access can be stated as a good achievement on the Hungarian online market, which means 4-5 purchases from 100 accesses, e.g. clicks. (Saleh et al., 2010)

In addition, we calculated the access (clicking) conversion on the base of private experiences -gained as a media designer 1 year long -of the ad (banner / image), $D M$, search engine optimization (keyword) or sub-page of the website (landing page) accesses. The performance and optimizing of marketing campaign can be analyzed at any time even including free programs, as Google Analytics, Google Adwords. These free or paid analytical evaluations summarize the company's statistics for that given period and point out the results of the breeding rate of return. After analyzing the statistics, the business decisions can be facilitated, the process becomes more predictable, and the key is that individual attitudes and habits and range of features of target group of the product and/or service can be formed which largely supports the company's competitive and efficient operation. Thus, this indicator as a separate segment shows the efficiency or effectiveness of used online marketing tools. To choose the right one, we need to clarify the conversion goals. [9] One of the most popular targets is to reach - really - online customers had to purchase, acquire subscribers, with participation in the sweepstakes, as well as market research/survey questionnaire is included. (Bíró, 2009)

\section{Methodology}

Our research methodology followed qualitative strategy, on the base of content analyses of in-depth interviews of online experts $(\mathrm{N}=7)$. We recorded the 
conversation and then we transcribed the data. Our questions were structured. The questioning went between 10 March 2016 and 18 May. 7 persons have taken part in the research, regarding to their profession they were mid, - or top managers and had at least 4 and maximum of 15 years of experience. Regarding to their activities, there are who is planning, leading and following up marketing and/or creative campaigns - together with analyses - or with full-service of online shop, online legal advising, retargeting and optimization services. Each interviewee serves the business-tobusiness trade.

The average age of them is about 31 years. The oldest interviewee is 38 , the youngest one was 25 years of age. All interviewees graduated from higher vocational education in economics, 3 persons received university qualifications, 4 persons received college degree. All residents are in the capital, Budapest, except 2 persons, who also live in the country "Pest". Two female and five male persons responded during the in-depth interviews. Two respondents asked for anonymity, so we omit insertion of the summary table referring to the small number of items, but we explain further content the in the following (position, work experience, scope of activity).

\section{Analyses of professional background of interviewees}

(1) Our first interviewee: He is a social media expert. Previously he has worked for the one of the biggest media agency -Kirowskilso Bar - as marketing advisor on email, online and social platforms. Recently he is dealing with online marketing and creative campaigns with a team covering 7 countries, as a Head of Social. He intends to be an effective intermediary between clients ordering campaign and among consumer purchases - which have been precisely positioned by him gained along with the joint work.

(2) Our second interviewee: He manages the one of the widest Internet advertising network of South-East Europe as an ad-serving leader. Since the inception of the company in 2006, it has become an exclusive partner of international and regional actors; they cover eight countries. Today the company is a quality partner of such publishers as MSN and Windows Live, Facebook, Miniclip, as well as leading local publishers. They treat the marketing campaigns uniformly to ensure the highest level of service at various surfaces such as display banners, rich media, search and video.

(3) Our third interviewee is a recognized Managing Director and an Internet and online legal expert. He founded the business with another person by having a decades-long legal experience. The company published quality certificates, as well as a book on the subject, besides online legal advisory.

(4) Our fourth interviewee: Considering his current position, he is responsible for the new markets (CEE Head of New Business). He started his unbroken career in 1999. Initially, he worked as an independent financial expert. Then, he has been working for companies providing online payments, mainly, as well as banking services; and secondly for a company, bringing together the global technology services, concerning the online sphere. The company is resident in Austria from 2016 but can be found on the Hungarian market also, with diverse range of activities.

(5) Our fifth interviewee: His current position is leader of a marketing department at a Conversion Optimizer tool/software provider company. The company's services are like popup, Call to Action, which means calling to action trying to save the departing visitors, by a CTA window, thus increasing the access rate of conversion rate. The promised conversion by them is 3-4\%, which are 3-4 purchases from 100 visitors. The company is developing a growing pace, as it is marketing services not 
only individually, but as a package; their services are also available bringing together, for example, companies operating web shop or server.

(6) Our sixth interviewee: He is the Head of PPC, i.e. Pay per Click team leader, so he knows a lot about advertising and statistical analysis side of Etarget, Google. In addition, web pages and web operations, SEO optimizations are also addressed. Besides the company's online campaigns - it is also available as a special package offer - it sells Yellow Pages phone books' print advertising surfaces as well.

(7) Our seventh interviewee has been working as a media supervisor for a classical media agency for years, where they manage both offline and online ads, however they do not deal with creative tasks. The online activity of them is fully extended; they offer AdWords, banner display, EDM, Facebook, mobile applications, online video, YouTube and search engine optimization inclusions.

\section{Hypotheses to be answered}

(H1) Hypotheses one

The professional web experts can provide a targeted, personalized offer for companies in any sectors of industry at any time, as to reach the proper target group.

$(\mathrm{H} 2)$ Hypotheses two

Starting a new web shop promises a proof of income in 2016 as it is an easy way to produce firm revenue for a business, nowadays.

(H3) Hypotheses three

The conversion rate is a reliable measure.

\section{Questions to be answered}

(Q1) Question one

Which are those measurable online marketing campaigns that determine the Hungarian online market? Is a sole online presence sufficient in order to achieve a secure corporate success?

(Q2) Question two

By various assurance certifications - quality product, data protection, legal compliance, ensuring low price, etc. - stated on the website the buying propensity can be increased - and thus also the extent of the conversion rate - in addition, arising mistrust can be reduced, as well.

\section{Results}

All of the respondents said that whether we serve the business or customer sector, besides the online advertising and optimizing methods the campaign should be supported by offline activities. These can be divided into two groups on the base of answers given by each respondent. The first is the replacement of the personal contact which can be experienced during the online activity. One of the means of supporting the online activity is related to this is the thorough and precise work of customer service or the active participation in professional conferences. Each of the respondents consider important to disclose the firm's activities and opportunities, even as a presenter. Including this, a typical way of gaining customers is tendering which is also based on personal relations. The other group - examined by me extends mainly to the B2B business trade. Here, the offline scopes of activity are grouping around the topic of education: trainings, newspaper appearances - like professional articles, interviews, case studies, etc. - or the opportunity of personal advisory. The conference participation also belongs to is, partially, in case it 
demonstrates the analyses of their activities with educational aims. The result of the survey - because the low number of items and its composition - is not representative. The interviewees were talking about the most important elements of the optimal and effective online marketing campaign, including the conversation rate and involuntary published data of web shop visitor, like Google or Gmail account, the logged profile on social media sites, etc. and statistical analyses of our browser which activities strengthen each other, closely. In case we analyze the reachable statistics of a potential customer properly, the conversation rate of us will increase quickly supporting the strengthening our competitiveness.

Whilst many conversation factors - external ones (uniqueness, availability, seasonality, etc.) and internal (maneuverability, informative, intelligibility) can affect the effectiveness of the channel of communication, considering them, analyzing them precisely can improve the efficacy of web sites. One can consider the eventuality of a sudden vim, mood which can provoke two different reactions from the same person also in case if she or he visits our site as a contributor.

\section{Our answered hypotheses}

(H1) Hypotheses one: 'The professional web experts can provide a targeted, personalized offer for companies in any sectors of industry at any time, as to reach the proper target group.'

This hypothesis has been denied. The campaign implemented 'at any time' is neither expedient nor profitable because it is important to consider the external and internal conversions as to reach the aims in a simple and effective way. Despite of this - as an example - we can meet a customer who wants to run his or her banner tomorrow already which can be realized with the staff available, however, but the optimal level of effectiveness cannot be reached this way, because the majority of its target group is on summer holidays, nationwide, and that's why they use the Internet less often.

We should consider such non-factors like the time available or timing. Differentiating is needed, because the timing of the campaign depends on cost frame available in a great extent.

Each interviewee, except one, told me that he cooperates with other companies if not directly but indirectly as a so called intermediary, convening the proper partners as to reach a successful campaign. The only exception is a group leader who manages the Facebook advertising platforms in 8 countries. He never meets this problem, because as a marketing agency, they are mandated all the time. They employ ready materials during their work and they do not offer out because they are overloaded, usually. Studying the hypotheses further, the reaching of "any industrial sector' occurred to me as a questionable one, but during the in-depth interviews conducted with colleagues of the agencies it has been revealed that they are able to serve 'any industrial sectors', indeed, recently. If not, then they can solve the problematic situations along with their social capital, as well. Obviously, a newly competing minor creative marketing agency (8-10 persons) would not do it well. Our last interviewee works with 12 fellows at a company which exists for 15 years, already. He also suggests the further recommendation and supports the cooperation with other companies in order to reach the common marketing aims, customized to the orderers' wishes. Thus, the trustworthiness, which is being built during the years and projects, is an important factor between the experts. In case of the online marketing campaigns the investments on the best opportunities can be lost if they are not timed, positioned or segmented properly. We extend our research on visiting minor agencies with maximum 8-10 persons, in the future. 
It is necessary for improvement of efficiency the - before mentioned - proper positioning and segmenting to which the adequate professional knowledge is provided for business-to-business members. In case we intend to reach the customers directly as web shop operators, worth to ask for advice or control of a professional online marketing expert even then, in order to reach an infallible success.

It is also important to pay attention to the product policy, the competitors, the new trends and customized sales promoting, besides the optimal timing.

The majority of the interviewees (5 persons, respondents 1, 2, 5, 6 and 7) stated, that in order to such an excellent operation, the agencies utilize analytical tools which not only monitor and analyze during surfing but conclude to possible outputs, e.g. the future purchase decisions.

The program is based on sophisticated system theory which is continuously developing. The aim of the analytical programs is the optimizing and increment of effectiveness, thus the enhancement of competitiveness, as well.

Our seventh interviewee said that there are threats, the so called 'ghost-accesses' against of which the firm has been succeeded so far. This means that they apply a permanent monitoring to filter the click-generating programs. All of this is carried out by a computer alarm program which should be upgraded continuously.

$(\mathrm{H} 2)$ Hypotheses two: 'Starting a new web shop promises a proof of income in

2016 as it is an easy way to produce firm revenue for a business, nowadays.'

Our second hypothesis has not been accepted either because although it is a possible 'easy' way to gain, however, we can be mistaken in many aspects without taking into account the before mentioned external and internal conversion factors.

On the base of analyses of experts' interviews, the interviewees - except 2 of them - named the income realization and the long term operation as 'easy' if the adequate social capital and financial resources are available. So if the company can afford money for marketing and it knows which media agency to turn to, then the 'easy going' is guaranteed. In case they do not avail the services provided by agencies, then a necessary condition is the targeted professional knowledge, such as online marketing, IT, marketing, logistics, bank sector and continuous mapping, analyses and development of them in order to appear and retain on the online market meeting the permanent innovation.

(H3) Hypotheses three: 'The conversion rate is a reliable measure.'

Our third hypothesis proved to be true because we got homogeneous results. The $100 \%$ of online experts I interviewed agreed with our statement. In our view, however, beyond the 'spirit-access sites' - which is filtered by agencies by an alarm program based on the IP address - further problems could arise with respect to the recontrolling.

There is a risk of the sole use of a single conversion value, as it distorts the results-for example, if an ad is clicked just by chance, or the cursor automatically adjusts and starts. They reach a separate count for the program, but in reality they are random events, of which you will never buy. When I asked it right after their response, all of them said that this failover occurs, indeed, but it is not common, and the optimization software can be set so sophisticatedly that access of actually not relevant consumers is almost completely excluded.

\section{Discussion}

In this chapter we briefly summarized the previously introduced 2 questions. 
(Q1) Question one: 'Which are those measurable online marketing campaigns that determine the Hungarian online market? Is a sole online presence sufficient in order to achieve a secure corporate success?'

Nowadays, the three most popular trends of Hungarian online market-offers in 2016 are the thematic, personalized online materials - such as courses, downloadable training materials and e-mail, or the web personalization. In addition, it has been said that the proper use of content marketing can increase our accesses, and our search engine optimization - such as application of a blog, a blog post promotion, the guest blogging, etc.

In addition, I got homogeneous results related to the business-to-business exchanges, in the selection of channels used in practice in the offline area, typically. Access to online conferences and professional presentations - for example: Conversion World - have become instruments of development of productivity, as usual. In association with it, the surveyed companies place a great emphasis on article publishing and advertising opportunities of trade journals. The use of these two offline channels is defining scopes of activities in corporate reputation as well as in widening the clientele.

(Q2) Question two: 'By various assurance certifications - quality product, data protection, legal compliance, ensuring low price, etc. - stated on the website the buying propensity can be increased - and thus also the extent of the conversion rate - in addition, arising mistrust can be reduced, as well.'

I got homogeneous result regarding the topic, again, after analyzing 4-1 in-depth interviews of online experts. All respondents used the answer-combinations 'yes' or 'yes, of course' - without hesitation. Although this result is reliable, as they are experienced professionals, it is not a representative one. I spread the number of interviewees, and as well as I intend to ask also consumers within the framework of a standardized questionnaire.

Figure 1

Logos of the "Reliable Shops" in Hungary

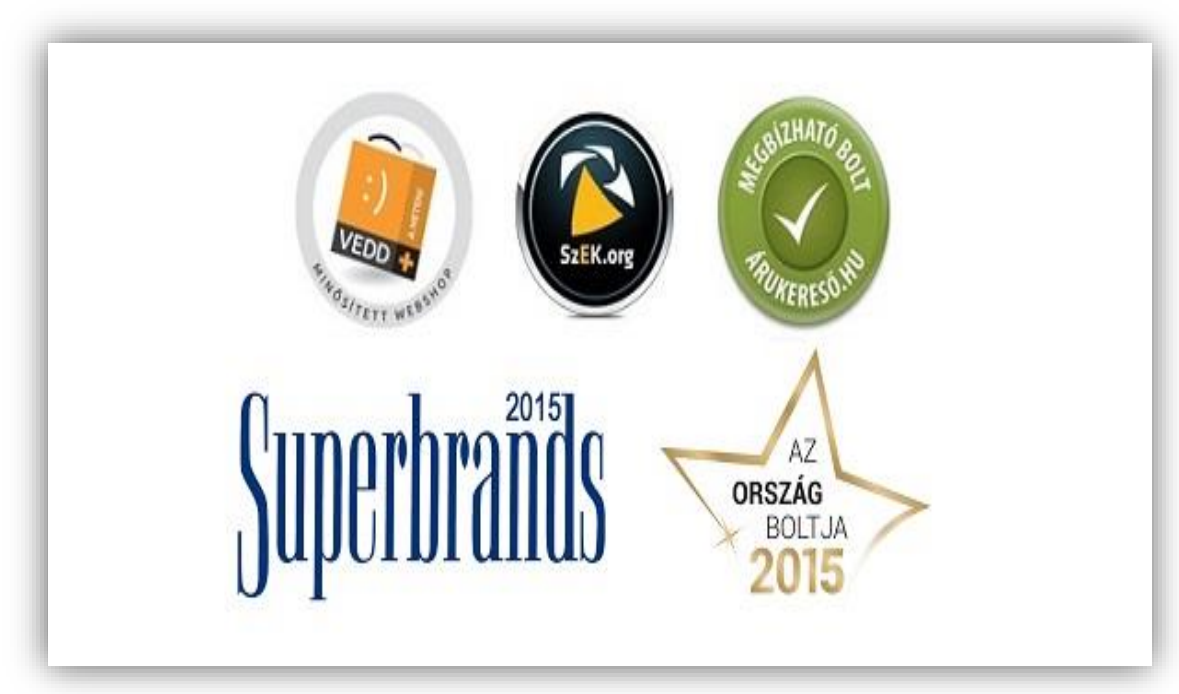

Source:https://lh3.googleusercontent.com/pb2krBhukUfFBvIJvf n7TsaZp7Tcfl2VbEjlp uwNHoFI weRupuv-CORCQ8FlgbiF-ynD4=s170 (10/05/2016) 


\section{Conclusion}

One of aims of this thesis was to research new, innovative, productivity-enhancing options and their tools, to estimate the volume of their efficiency and reliability, as well as introduce the Hungarian market index measurement used in practice. We found the current conversion rates correct based on our research, but nevertheless we rejected the hypothesis of bias 'ghost' on purpose. From point of view of our investigation of the effectiveness of online marketing, the first step of a start-up web shop is to fix the web site content and formal requirements, or even still needs to develop it before advertising the start of the distribution. Then, follow-up and comparing the continuous statistics, the individual consumer habits, attitudes and characteristics that are relevant to the company's product/service terms can be emphasized.

So despite of our results and optimization programs, we have to continue testing the target groups/s, permanently, by changing the several promoting tools as well as some design components like varying of layout or colors. [1] The consumer behavior groups established such way follow a relatively similar behavior, so based on the adequate number of access statistics a more targeted and effective marketing message can be fed to the visitors, by which the purpose of the message can reach the success with a greater chance, and the shopping phase continuing testing can be reached more rapidly.

Another aim of this study was to introduce the most frequently used tools and measurement capabilities of Hungarian online and offline marketing campaigns, relevant in practice, in business-to-business market. Among our respondents, there were the participants of B2B, and members of the two-player supply-chain where the trader, the retailer and the consumer also are located among partners. Our further goal was to emphasis their influence and effectiveness, as well as potential dangers.

The web shop operators take a great care to show the full online extensions, paying particular attention to mobile as to ensure adequate competitiveness. In addition, the sleek design, user friendly, concise, yet informative content marketing is essential to support both - business and consumer - sectors. (Loveday at al., 2007) Our conclusions have resulted in professional circles queried, based on analysis of the content of structured in-depth interviews.

The limitations of our study were the low number of the elements what I would like to expand in the next semesters.

After completing the recent phase of the study, we believe that the online market research topic is still containing a lot of alternatives and research potential. The picked up online shopping is to peak until 2018-20202 that is why we research the topic further. In the future, we plan to observe, analyze and compare the changes in the direction of the development of two nationalities involved. We hope that we will have chances more often in the future to work with online marketing opportunities and conduct new researches and explore new models and trends this way.

\footnotetext{
2 Advertising and Marketing, "Internet to Hit 3 Billion Users in 2015", available at:
} http://www.emarketer.com/Article/Internet-Hit-3-Billion-Users-2015/1011602 (19/04/2016) 


\section{References}

1. Advertisting and Marketing, "Internet to Hit 3 Billion Users in 2015", available at: http://www.emarketer.com/Article/Internet-Hit-3-Billion-Users-2015/1011602 (16/04/2016)

2. Bíró P. (2009), "Marketing nélkülnemmegy", Budapest

3. Fehér, M. (2013), "Mifánterem a konverzió?", available at: http://www.onlinemarketing-akademia.hu/blog/2013/02/mi-fan-terem-a-konverzio-1/ (06/05/2016)

4. Google.com, "Logos of the "Reliable Shops" in Hungary", available at: https://lh3.googleusercontent.com/pb2krBhukUfFBvlJvf_n7TsaZp7Tcfl2VbEjlp_uwNHoFI weRupuv-CORCQ8FlgbiF-ynD4=s170 (10/05/2016)

5. KSH, "Rendszeresinternethasználókaránya" (2004-2015), available at: https://www.ksh.hu/docs/hun/eurostat_tablak/tabl/tin00091.html (19/04/2016)

6. Loveday L., Sandra Niehaus (2007), "Web design for ROl"

7. Majláth, M., Kelemen-Erdős, A. (2015), "Marketingkommunikáció segédanyag", Budapest

8. Saleh K., ShukairyA. (2010), "Conversion Optimalization: The Art of Science of Converting Prospects to Customers"

9. Szabó, F. (2008), "Azinternetesaranybánya", Budapest

10. Virányi, P. (2014) "Több mint reklámtörténelem", Gondolat Kiadó, Budapest

\section{About the authors}

Katalin Tari is a Ph.D. Candidate on the Faculty of Economics and Social Sciences Institute in Szentlstván University (Hungary, Gödöllő). Her scientific research reads about the Hungarian online marketing trends, changes, develop of the e-commerce furthermore she investigates the Hungarian e-food sales and the worldwide wine behaviors - offline and online - sales with higher attention. Previously she has got her Master's Degree at the same University where she specialized in Marketing strategy therefore graded Excellent with Honors and a professional qualification of the Doctoral School of Management and Business. She has absolved a second Master's (M.Sc.) Degree program, in German-Hungarian Translator as well. Author can be contacted at katalintari@gmail.com.

Nikolett Mihaly Ph.D. is an Assistant Professor of Economic Psychology at the Department of Marketing, Faculty of Economics and Business, at University of Gödöllö. Her current research areas are financial consciousness and higher education institution management. She is the (co)author of number of articles in international and national journals. She is actively engaged in number of scientific projects and collaborates in several applied projects in the field of financial education. Author can be contacted at mihaly.nikolett@gtk.szie.hu. 